\title{
Subproteomic analysis of basic proteins in aged skeletal muscle following offgel pre-fractionation
}

\author{
JOAN GANNON $^{1}$ and KAY OHLENDIECK ${ }^{2}$ \\ ${ }^{1}$ Laboratory of Systems Medicine and Cell Biology, Department of Medicine, Research Institute of \\ McGill University Health Centre, Montreal, QC, Canada; ${ }^{2}$ Muscle Biology Laboratory, \\ Department of Biology, National University of Ireland, Maynooth, Republic of Ireland
}

Received October 19, 2011; Accepted December 21, 2011

DOI: $10.3892 / \mathrm{mmr} .2012 .759$

\begin{abstract}
The progressive loss of skeletal muscle mass is a serious pathophysiological problem in the elderly, which warrants detailed biochemical studies into the underlying mechanism of age-related fiber degeneration. Over the last few years, mass spectrometry (MS)-based proteomics has identified a considerable number of new biomarkers of muscle aging in humans and animal models of sarcopenia. However, interpretation of the proteomic findings is often complicated by technical and biological limitations. Although gel electrophoresis-based approaches represent a highly sensitive analytical way for the large-scale and high-throughput survey of global changes in skeletal muscle proteins during aging, often the presence of components with an isoelectric point in the basic range is underestimated. We, therefore, carried out a comparative subproteomic study of young versus aged rat muscle focusing on potential changes in muscle proteins with an alkaline isoelectric point, using a combination of offgel electrophoresis and two-dimensional (2D) slab gel electrophoresis. Offgel electrophoresis was successfully applied as a prefractionation step to enrich basic protein species from crude tissue extracts representing young adult versus senescent muscle specimens. Proteomics has demonstrated alterations in a small cohort of basic proteins during muscle aging. The mass spectrometric identification of altered proteins and immunoblotting revealed a decrease in the glycolytic enzyme glyceraldehyde-3-phosphate dehydrogenase (GAPDH) and a
\end{abstract}

Correspondence to: Professor Kay Ohlendieck, Department of Biology, National University of Ireland, Maynooth, Co. Kildare, Republic of Ireland

E-mail: kay.ohlendieck@nuim.ie

Abbreviations: 2D, two-dimensional; Akt/PKB, protein kinase B; $\mathrm{CK}$, creatine kinase; GAPDH, glyceraldehyde-3-phosphate dehydrogenase; IEF, isoelectric focusing; MS, mass spectrometry; SDS, sodium dodecyl sulfate; PAGE, polyacrylamide gel electrophoresis; PBS, phosphate-buffered saline

Key words: aging, muscle aging, muscle proteomics, offgel electrophoresis, sarcopenia concomitant increase in mitochondrial creatine kinase $(\mathrm{CK})$ and ubiquinol cytochrome-c reductase. This agrees with the idea of a glycolytic-to-oxidative shift during muscle aging, which is indicative of an overall fast-to-slow transition process in senescent rat muscle. Thus, alterations in the abundance of metabolic enzymes appear to play a central role in the molecular pathogenesis of age-dependent muscle wasting.

\section{Introduction}

The progressive wasting of skeletal muscle tissue plays a crucial pathophysiological role in frailty, fragility and loss of independence in aged people (1). In the majority of humans, skeletal muscle mass and contractile strength decline during aging (2), making sarcopenia a striking feature of the senescent organism (3). A sedentary life style clearly promotes muscle degeneration in elderly patients (4). Functional impairments of the neuromuscular system are believed to be multi-factorial, but it is not clear whether a pathobiochemical hierarchy exists within these aberrant pathways $(5,6)$. The exact molecular mechanisms underlying primary muscle degeneration, secondary effects, impaired repair cycles and physiological adaptations of aging muscle are still elusive. Although considerable inter-individual differences exist in elderly people with respect to the degree of muscle wasting $(7,8)$, the age-related impairment of innervation and concomitant excitation-contraction uncoupling appears to be an intractable consequence of advanced age (9).

Although it is encouraging that a protein-rich diet and regular physical activity can at least partially diminish severe fibre degeneration (10-12), the symptoms of sarcopenia may be aggravated by unrelated pathologies. This includes cancer, traumatic injury, type 2 diabetes, metabolic syndrome, renal failure, chronic obstructive pulmonary disease and congestive heart failure (13-15). Thus, the clinical prevalence of sarcopenia in the aging population requires detailed physiological, biochemical and genetic investigations into the molecular pathogenesis of age-related muscle degeneration. In the present study, we used electrophoresis-based proteomics to study potential changes in muscle protein abundance in an established animal model of sarcopenia, the aged Wistar rat (16). Over the last few years, a variety of proteomic approaches have determined changes in animal and human 
muscle proteins during aging (17). This includes the mass spectrometric (MS) identification of altered protein nitration (18), protein phosphorylation (19), protein carbonylation (20) and protein glycosylation (21), as well as changes in the abundance of muscle proteins using crude tissue extracts (22-27) and subcellular fractions, such as myofibrils (28), integral membrane proteins (29) and mitochondria (30).

Modifications in mitochondria have previously been implicated in the natural aging process (31), including cellular senescence in contractile tissues (32). Functional changes and altered expression patterns of mitochondrial proteins in aged skeletal muscle have been confirmed by proteomic investigations, as reviewed by Staunton et al (33). However, a potential problem with the gel electrophoretic separation of the urea-soluble portion of the skeletal muscle proteome is that the presence of proteins that exhibit an isoelectric point in the basic range is often underestimated (34). To address this technical problem, we carried out an offgel electrophoretic pre-fractionation step prior to standard 2D gel electrophoresis. The offgel approach fractionates protein populations in solution by isoelectric focusing (IEF) (35) and can therefore be employed to separate proteins with small differences in their isoelectric point (36). Offgel electrophoresis has been successfully applied to studying extraocular muscle specimens (37) and was used here for a comparative subproteomic study of young adult versus aged rat muscle. Our proteomic survey has focused on potential changes in proteins with a basic isoelectric point and showed an increase in mitochondrial creatine kinase $(\mathrm{CK})$ and ubiquinol cytochrome-c reductase and a decrease in glyceraldehyde-3-phosphate dehydrogenase (GAPDH). These findings agree with the idea that muscle aging is associated with a glycolytic-to-oxidative shift and that changes in key metabolic enzymes are involved in age-related muscle weakness.

\section{Materials and methods}

Materials. Chemicals and materials for the offgel and 2D gel electrophoretic analysis of muscle proteins, including IEF $\mathrm{pH}$ gradient strips and ampholytes, were obtained from Agilent Technologies (Santa Clara, CA, USA) and Amersham Bioscience/GE Healthcare (Little Chalfont, Bucks, UK). Ultrapure Protogel acrylamide stock solutions were purchased from National Diagnostics (Atlanta, GA, USA). For the generation of peptides, sequencing grade-modified trypsin was obtained from Promega (Madison, WI, USA). Protease inhibitors, nitrocellulose sheets and chemiluminescence substrate were from Roche Diagnostics (Manheim, Germany), Millipore (Bedford, MA, USA) and Pierce and Warriner (Chester, UK), respectively. For immunoblotting, primary antibodies were purchased from Abcam (Cambridge, UK), (pAb to GAPDH; and $\mathrm{mAb} 46 \mathrm{~A} 1$ to $\mathrm{CK}$ ) and Upstate Biotechnology (Lake Placid, NY) [mAb SKB1 to protein kinase B (Akt/PKB)]. Secondary peroxidase-conjugated antibodies were from Chemicon International (Temecula, CA). All other chemicals were of analytical grade and obtained from Sigma Chemical Company (Dorset, UK).

Animal model of sarcopenia. The gastrocnemius muscle from young adult versus aged Wistar rats was used for the subproteomic analysis of aging, focusing on proteins with an isoelectric point in the basic range. Aged Wistar rat muscle is an internationally established model system to study agedependent changes in sarcopenia (16). Both human and rodent muscles share many common age-related alterations, including the incomplete recruitment of distinct fiber groupings, altered proportions between slow and fast fibers, altered fiber size, tissue degeneration and contractile weakness (5). This makes rat muscle an ideal tissue source for detailed proteomic studies of muscle wasting associated with aging. Freshly dissected muscle specimens from 3- and 30-month-old rats were obtained from the Animal Facility of the Department of Physiology, Trinity College Dublin, Ireland. For one set of comparative proteomic analyses, a combination of 6 biological repeats was carried out for each age group. All rats used in this study were fed ad libitum and kept at a standard light-dark cycle with unrestricted movement in standard animal house cages (26). The activity level of the younger rat population was enhanced as compared to the older cohort.

Preparation of crude skeletal muscle extracts for electrophoretic analysis. Fresh muscle tissue (100 mg) was quick-frozen in liquid nitrogen and ground into a fine powder using a pestle and mortar. The pulverized muscle tissue was resuspended in $1 \mathrm{ml}$ of ice-cold buffer (7 M urea, $2 \mathrm{M}$ thiourea, $65 \mathrm{mM}$ Chaps, $10 \mathrm{mM}$ Trizma base, $1 \%$ ampholytes, $100 \mathrm{mM}$ DTT). To avoid protein degradation and eliminate excessive viscosity of the extract due to DNA, the solution was supplemented with a protease inhibitor cocktail (Roche Diagnostics), and $2 \mu \mathrm{l}$ of DNase-I (200 units, Sigma Chemical Company) was added per $100 \mu \mathrm{l}$ buffer (26). The tissue homogenate was mixed by vortexing and was then placed on a bench top shaker for $2.5 \mathrm{~h}$ at room temperature to precipitate the total protein fraction. The suspension was centrifuged at 20,000 x g in an Eppendorf 5417R centrifuge (Eppendorf, Hamburg, Germany) for $20 \mathrm{~min}$. The resulting protein pellet was washed in $5 \mathrm{ml}$ of ice-cold $100 \%$ acetone and thoroughly broken up by vortexing and sonication. The centrifugation and washing step was repeated twice more with $80 \%$ acetone and the final protein precipitate was collected by centrifugation and resuspended in $1 \mathrm{ml}$ of the above described buffer by gentle pipetting and vortexing. The protein lysate was then incubated for $1 \mathrm{~h}$ at room temperature, whereby samples were vortexed every $10 \mathrm{~min}$ for $5 \mathrm{sec}$, and then subjected to IEF.

Offgel electrophoresis. The initial separation of the acidic versus the basic protein cohort from rat gastrocnemius muscle was carried out with a 3100 OFFGEL Fractionator from Agilent Technologies. Protein samples were pre-fractionated on 24-well lanes across 24 cm IPG pH 3.0-10.0 strips (35). In order to enrich the acidic and the basic portion of the muscle sample, proteins from wells 1-12 (acidic samples) and wells 13-24 (basic samples) were pooled, respectively, upon completion of IEF. The Agilent 3100 OFFGEL Fractionator performs IEF of proteins in immobilized $\mathrm{pH}$ gradient strips while the separated proteins can then be recovered from the liquid phase (36). The offgel electrophoresis procedure was carried out according to the manufacturer's guideline using reagents supplied with the OFFGEL pH 3.0-10.0 kit from Agilent. Fifteen minutes prior to IEF, IPG strips were incubated with 
$40 \mu \mathrm{l}$ of $1 \mathrm{X}$ protein OFFGEL stock solution. Samples were run at $1 \mathrm{mg}$ of protein sample/lane for our comparative study of young adult versus aged muscle. The sample protein volume was brought up to $0.72 \mathrm{ml}$ with $\mathrm{ddH}_{2} \mathrm{O}$, and added to $2.88 \mathrm{ml}$ of $1.25 \mathrm{X}$ protein OFFGEL stock solution. A $150-\mu 1$ aliquot of this solution was then added to each well. IEF strips were focused in four stages, using $200 \mathrm{~V}$ for $90 \mathrm{~min}, 2,000 \mathrm{~V}$ for $90 \mathrm{~min}$, $3,000 \mathrm{~V}$ for $90 \mathrm{~min}$ and a final 5,000 V step until the procedure reached $64 \mathrm{kV} / \mathrm{h}$. Total focusing time depended mainly on the number of strips being focused and could take up to $72 \mathrm{~h}$ when 12 strips were run simultaneously. Every $24 \mathrm{~h}$ the wicks on each strip were removed and replaced with new wicks wetted with distilled water. Upon completion of IEF, samples from the two different $\mathrm{pH}$-ranges were removed and pooled. Excess urea, which was found to interfere with the acetone precipitation of protein, was removed by repeated dialysis. Samples were acetone precipitated (26) and resuspended in $200 \mu \mathrm{l}$ of rehydration buffer (7 $\mathrm{M}$ urea, $2 \mathrm{M}$ thiourea, $65 \mathrm{mM}$ Chaps, $1 \%$ ampholytes $\mathrm{pH} 3.0$ to 10.0 and $10 \mathrm{mg} / \mathrm{ml}$ DTT).

Two-dimensional (2D) gel electrophoretic analysis. In order to analyze pre-fractionated proteins with an isoelectric point in the basic range, 2D gel electrophoresis was carried out as previously described in detail by our laboratory $(19,26,28)$. Following IEF with an Amersham IPGphor system with the following running conditions: $30 \mathrm{~V}$ for $2 \mathrm{~h}, 500 \mathrm{~V}$ for $2.5 \mathrm{~h}$, $1,000 \mathrm{~V}$ for $1 \mathrm{~h}, 2,000 \mathrm{~V}$ for $1 \mathrm{~h}, 4,000 \mathrm{~V}$ for $1 \mathrm{~h}, 6,000 \mathrm{~V}$ for $1 \mathrm{~h}, 800 \mathrm{~V}$ for $3 \mathrm{~h}, 500 \mathrm{~V}$ for $1.5 \mathrm{~h}$ and finally $8,000 \mathrm{~V}$ for $2.5 \mathrm{~h}$, samples were equilibrated and washed in running buffer (26), and then separated in the second dimension with $12 \%$ resolving gels in a Protean Xi-ll cell from Bio-Rad Laboratories (Hemel-Hemstead, Hertz, UK). Sodium dodecyl sulfate (SDS)-polyacrylamide gel electrophoresis (PAGE) was carried out for $2 \mathrm{~h}$ at $30 \mathrm{~V}$ and a subsequent $80 \mathrm{~V}$ step until the bromophenol blue dye front ran off the gel. Silver staining of 2D gels was carried out by the method of Chevallet et al (38). For image analysis, 6 gels representing young adult muscle and 6 gels representing aged muscle were scanned using Image Scanner II from Amersham Bioscience/GE Healthcare. Images were analyzed with Progenesis SameSpots analysis software from Nonlinear Dynamics (Newcastle upon Tyne, UK).

Mass spectrometric (MS) identification of basic muscle proteins. Protein identification was carried out by MS analysis of peptides with a Model 6340 Ion Trap LC/MS apparatus from Agilent Technologies. Excision, washing, destaining and treatment with sequencing-grade trypsin were performed using an optimized method as previously described by our laboratory $(28,30)$. Trypsin-generated peptides were resuspended in $30 \mu \mathrm{l}$ of ultrapure $\mathrm{ddH}_{2} \mathrm{O}$ and $0.1 \%$ formic acid for ion trap LC-MS analysis. Separation of peptides was performed with a Nanoflow Agilent 1200 series system (Agilent Technologies), equipped with a Zorbax 300SB C18 $5 \mu \mathrm{m}, 4 \mathrm{~mm} 40 \mathrm{nl}$ pre-column and an Zorbax 300SB C18 $5 \mu \mathrm{m}, 43 \mathrm{~mm}$ x $75 \mu \mathrm{m}$ analytical reversed phase column using HPLC-Chip technology. Mobile phases utilized were A, $0.1 \%$ formic acid; B, $50 \%$ acetonitrile and $0.1 \%$ formic acid. Samples $(15 \mu \mathrm{l})$ were loaded into the enrichment at a capillary flow rate set to $4 \mu \mathrm{l} / \mathrm{min}$ with a mix of $\mathrm{A}$ and $\mathrm{B}$ at a ratio 19:1. Tryptic peptides were eluted with a linear gradient of $10-90 \%$ solvent B over 40 min with a constant nano pump flow of $0.60 \mathrm{ml} / \mathrm{min}$. A $10 \mathrm{~min}$ post time of solvent A was used to remove sample carryover. The capillary voltage was set to $1,700 \mathrm{~V}$. The flow and the temperature of the drying gas was $4 \mathrm{l} / \mathrm{min}$ and $300^{\circ} \mathrm{C}$, respectively. For muscle protein identification, database searches were carried out with Mascot MS/MS Ion search (Matrix Science, London, UK). All searches used 'Rattus norvegicus' as taxonomic category and the following parameters: i) two missed cleavages by trypsin, ii) mass tolerance of precursor ions $\pm 2.5 \mathrm{Da}$ and product ions $\pm 0.7 \mathrm{Da}$, iii) carboxymethylated cysteine fixed modification and iv) oxidation of methionine as variable modification. In addition, the percentage coverage was set at over $10 \%$, with at least 2 matched distinct peptide and a Mascot score of over 60 .

Immunoblot analysis. For the verification of changes in select marker proteins, immunoblotting was used to determine potential changes in proteins in young adult versus aged muscle preparations (26). The electrophoretic transfer of proteins to Immobilon NC-Pure nitrocellulose membranes was carried out with a Mini-Protean II transfer system from Bio-Rad Laboratories (Hemel-Hempstead, Herts, UK). Following transfer for $1 \mathrm{~h}$ at $100 \mathrm{~V}$ and $4^{\circ} \mathrm{C}$, the efficiency of transfer was evaluated by Ponceau-S-Red staining of membranes, followed by de-staining in phosphate-buffered saline (PBS, $50 \mathrm{mM}$ sodium phosphate, $0.9 \%$ (w/v) $\mathrm{NaCl}, \mathrm{pH} 7.4$ ). Protein-containing nitrocellulose membranes were blocked for $1 \mathrm{~h}$ in $5 \%$ (w/v) fat-free milk powder in PBS and incubated for $3 \mathrm{~h}$ at room temperature with appropriately diluted primary antibodies to GAPDH, CK or Akt/PKB. Following washing in blocking solution, sheets were incubated with an appropriate dilution of peroxidase-conjugated secondary antibody for $1 \mathrm{~h}$ at room temperature, washed again in blocking solution and PBS, and finally immuno-decorated protein bands were visualized using the SuperSignal-Type enhanced chemiluminecence system from Pierce and Warriner (Chester, Cheshire, UK). Densitometric scanning of immunoblots was performed on a Molecular Dynamics 300S computing densitometer (Sunnyvale, CA, USA) with Imagequant V3.0 software.

\section{Results}

Certain muscle proteins with an isoelectric point in the basic range are underestimated in gel electrophoresis-based proteomic studies. Therefore, to address this technical issue, we performed a comparative subproteomic investigation of young adult versus aged rat muscle focusing on potential changes in muscle proteins with an alkaline isoelectric point. The combination of offgel electrophoresis and 2D gel electrophoresis is outlined in Fig. 1 and the separation patterns in the basic pH-range are shown in Fig. 2 that compares young adult versus aged muscle specimens. A mastergel of proteins with age-related changes in abundance and their mass spectrometric identification is presented in Fig. 3 and Table I. Verification of proteomic data is provided by comparative immunoblot analysis of select marker proteins (Fig. 4).

Offgel electrophoretic separation of the skeletal muscle proteome. In order to improve protein separation in the basic $\mathrm{pH}$-range, offgel electrophoresis was employed as a prefractionation step. Running conditions were optimized with 


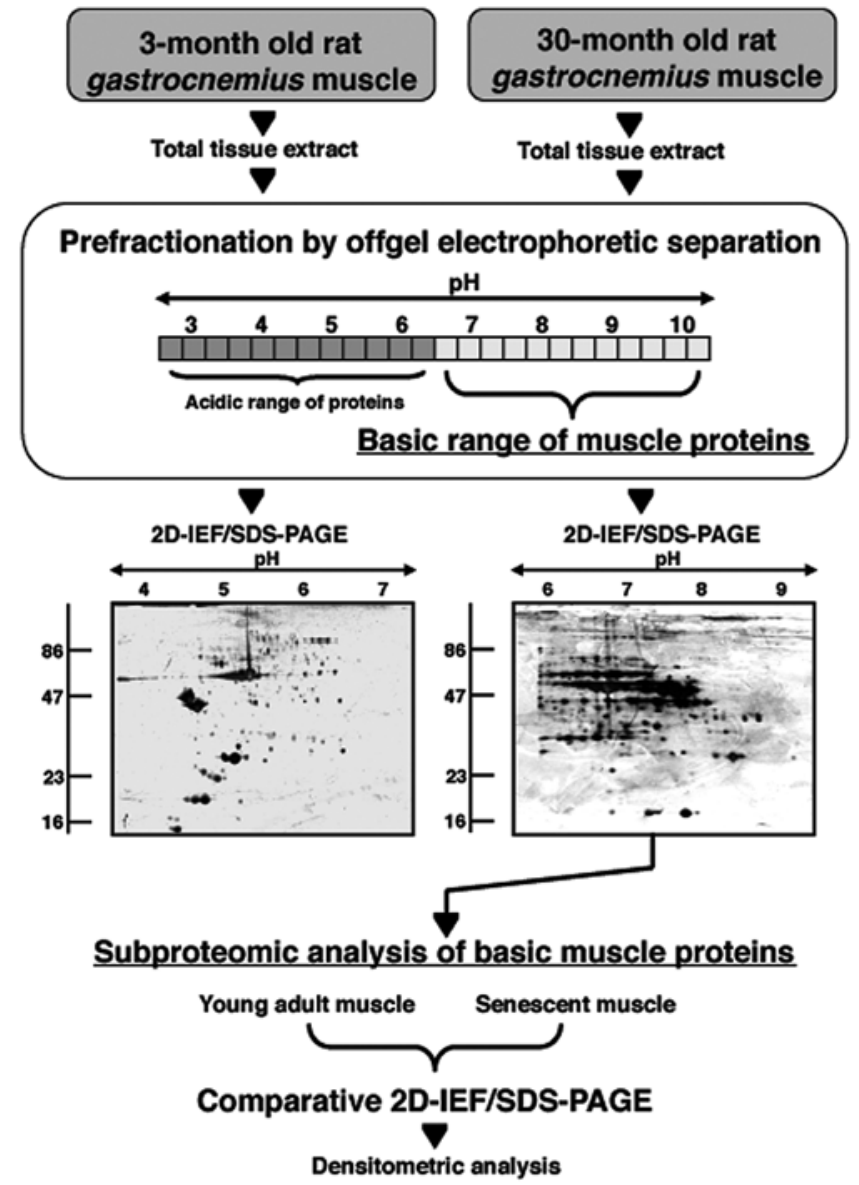

Mass spectrometric identification of changed proteins

$\nabla$

Verification of proteomic findings by immunoblot analysis

Figure 1. Analytical work-flow diagram for studying the basic protein changes during skeletal muscle aging. Shown is a flow diagram of the pre-fractionation approach using offgel electrophoresis in order to enrich for muscle proteins with a basic pI-value. Shown are representative silver-stained 2D gels of the acidic vs. alkaline range of proteins following separation by offgel electrophoresis. The subproteomic analysis of young adult vs. aged muscle proteins was then performed by $2 \mathrm{D}$ gels employing a $\mathrm{pH}$ 6.0-11.0 range.

respect to loading volume and protein amounts needed for a proper offgel electrophoresis-based separation of muscle proteins (data not shown). An amount of $1 \mathrm{mg}$ protein/lane resulted in an acceptable rate of protein recovery following offgel electrophoresis, dialysis and acetone precipitation for protein fractionation, removal of access urea and protein concentration, respectively. Fig. 1 outlines the various experimental steps used in the analysis of the basic protein cohort from young versus aged gastrocnemius muscle. The silverstained 2D gels of the acidic complement versus the basic cohort of urea-soluble muscle proteins show a comparable protein separation for the $\mathrm{pH}$ 4.0-7.0 range and an improved separation pattern for the $\mathrm{pH}$ 6.0-9.0 range, as compared to previously published 2D maps of crude skeletal muscle preparations (24-26).

Gel electrophoretic comparison of young adult versus aged skeletal muscle. The 2D gels presented in Fig. 2 illustrate the expression pattern of basic proteins from young adult versus aged rat gastrocnemius muscle. Both gels show a relatively comparable 2D protein spot distribution in the $\mathrm{pH}$ 6.0-11.0 range. In order to determine potential changes in abundance in individual protein spots, gels were analyzed with Progenesis SameSpots analysis software. The densitometric analysis of the $2 \mathrm{D}$ gels revealed 12 muscle-associated proteins with an altered abundance. Of these differentially expressed protein species, 6 protein isoforms could unequivocally be identified by MS.

Mass spectrometric (MS) identification of muscle proteins with an age-related change in abundance. The representative mastergel in Fig. 3 shows the 6 identified proteins that differed in their abundance between young adult and senescent muscle preparations. Proteins ranged in molecular mass from 36-48 kDa and exhibited an isoelectric point from pI 6.6-9.1. Table I lists spot numbers, protein accession numbers, name of identified proteins, number of matched peptides, peptide sequences, sequence coverage, molecular mass, isolectric point, Mascot score and fold-change of individual protein species during aging. Listed are muscle-associated protein with a Mascot score above 60 . Protein spots with an increased density were identified as two key mitochondrial components, the mitochondrial isoform of CK (spot 1) and ubiquinol cytochrome-c reductase (spot 2). A reduction was shown for the muscle-type CK (spot 3) and the glycolytic enzyme GAPDH (spots 4-6).

Immunoblot analysis of marker proteins in aging skeletal muscle. In order to verify the differential expression of muscle-associated components that was identified by our proteomic survey of basic proteins, immunoblotting was carried out. Fig. 4 illustrates the immuno-decoration of $\mathrm{CK}$ versus GAPDH, as well as Akt/PKB as a loading control. In agreement with the proteomic establishment of an increased level of mitochondrial $\mathrm{CK}$ and a decreased concentration of GAPDH, immunoblot analysis showed a significant elevation of the mitochondrial enzyme and suggests a reduced presence of the glycolytic protein in aged skeletal muscle.

\section{Discussion}

As the primary site for energy generation via oxidative phosphorylation, mitochondria play a key role in skeletal muscle metabolism. In addition, this class of organelle is involved in protein transportation, cell cycle progression, calcium handling, intermediary metabolism and apoptotic regulation (39). Alterations in the abundance and/or post-translational modifications of mitochondrial enzymes are believed to be involved in the natural aging process (40). In addition, altered concentration levels of mitochondrial enzymes from skeletal muscle are often an indication of fiber type shifting during physiological or pathophysiological muscle adaptations (41). In this respect, the findings presented in this subproteomic survey of basic proteins in young adult versus senescent rat gastrocnemius muscle support the idea of a glycolytic-to-oxidative shift during skeletal muscle aging. The mass spectrometric identification of altered basic proteins has established an increase in two key mitochondrial enzymes, ubiquinol cytochrome-c reductase core protein 2 and mitochondrial CK and a concomitant 


\section{Young adult muscle}

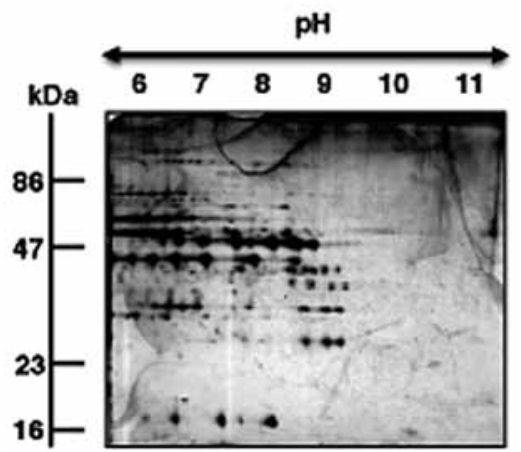

Aged muscle

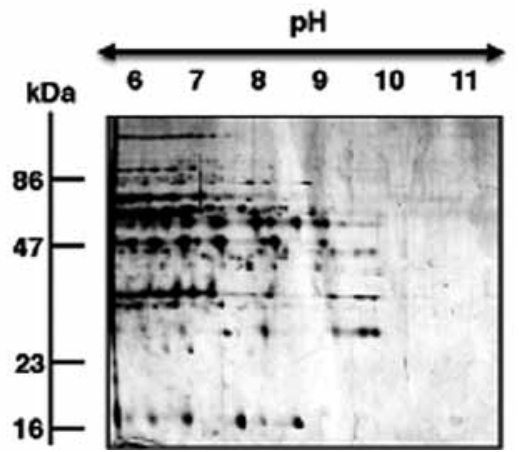

Figure 2. Comparative 2D gel electrophoretic analysis of basic proteins during skeletal muscle aging. Shown are 2D gels of young adult vs. aged rat gastrocnemius muscle preparations. The $\mathrm{pH}$-values of the first dimension gel system and molecular mass standards (in $\mathrm{kDa}$ ) of the second dimension are indicated on the top and on the left of the panels, respectively.

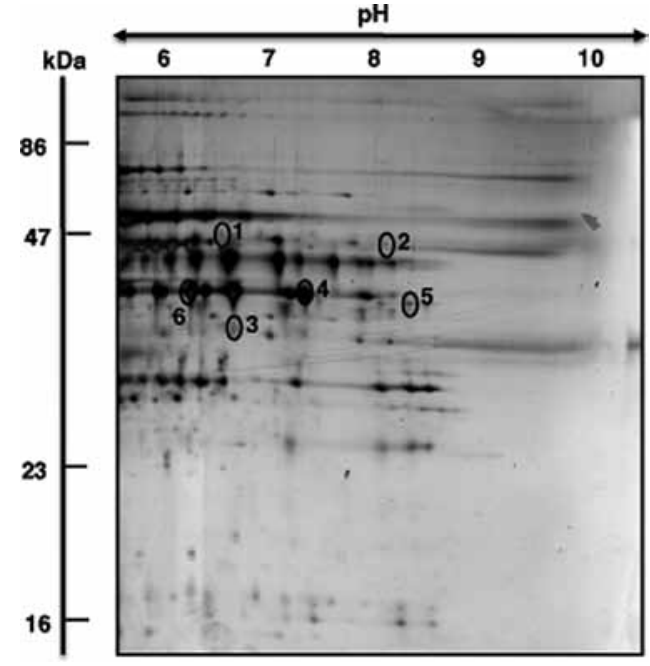

Figure 3. Proteomic identification of altered proteins during skeletal muscle aging. Shown is a representative 2D mastergel of proteins with differential expression in aged rat gastrocnemius muscle. Identified protein spots are numbered 1-6 and their mass spectrometric identification is listed in Table I. The $\mathrm{pH}$-values of the first dimension gel system and molecular mass standards (in $\mathrm{kDa}$ ) of the second dimension are indicated on the top and on the left of the panels, respectively.

decrease in the glycolytic marker enzyme GAPDH in senescent rat muscle. This metabolic shift would imply a fast-to-slow muscle transformation process during age-related adaptations of contractile fibers. The mitochondrial and glycolytic aging markers identified in this study are enzymes with well-characterized metabolic functions. CK is a key metabolic enzyme of the mitochondrial inter-membrane space and is involved in the production of creatine phosphate from mitochondrial ATP and cytosolic creatine (42). Ubiquinol cytochrome-c reductase is an essential subunit of the cytochrome-bcl complex, making it a crucial element of the mitochondrial respiratory chain (43). GAPDH is a key enzyme of the glycolytic pathway that converts glyceraldehyde-3-phosphate to 1,3-bisphosphoglycerate and generates NADH (44).

Previous proteomic studies of both human and animal muscles have shown a general trend of muscle transitions
A CK
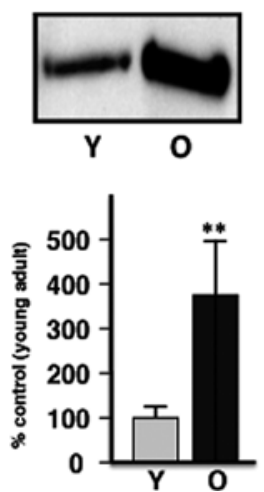

B GAPDH
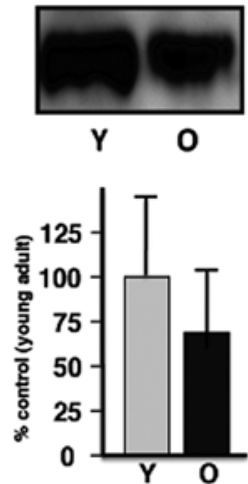

C Akt/PKB
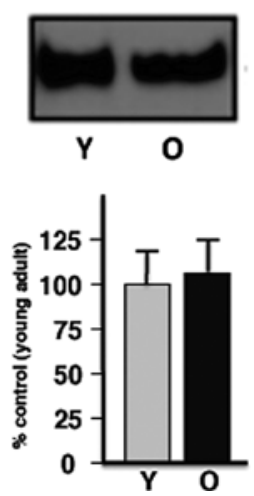

Figure 4. Verification of select proteomic data by immunoblotting. Shown is an expanded view of immuno-decorated bands from young adult (Y) vs. old $(\mathrm{O})$ skeletal muscle preparations, representing $(\mathrm{A})$ creatine kinase $(\mathrm{CK})$, (B) glyceraldehyde-3-phosphate dehydrogenase (GAPDH) and (C) Akt/PKB, respectively. The comparative immunoblot analysis was statistically evaluated using an unpaired Student's t-test $\left(n=6,{ }^{* *} \mathrm{P}<0.01\right)$.

to more aerobic-oxidative metabolism in a slower-twitching aged fiber population (22-30). This would agree with the results of the subproteomic analysis of basic muscle proteins presented in this study. Aged muscle fibers are under considerable oxidative stress and exhibit mitochondrial abnormalities (45-47). Importantly, changes in the abundance of mitochondrial versus glycolytic enzymes are often accompanied by shifts in fiber type distribution patterns of individual muscles (48). For example, chronic low-frequency stimulation triggers a gradual shift towards slower isoforms of contractile and calcium handling proteins, as well as a drastic increase in mitochondrial enzymes (49). The same alterations in metabolic enzymes have been described in the case of pathological fiber type transitions. The proteomic profiling of the ADR mouse model of myotonia has clearly shown increased levels of mitochondrial enzymes in hyper-excitable muscle tissue (50). With respect to sarcopenia, the exact extent of a glycolytic-to-oxidative shift and accompanying fast-to-slow muscle transformation process is still the subject of intense debate in the field of biogerontology. Both human and animal 


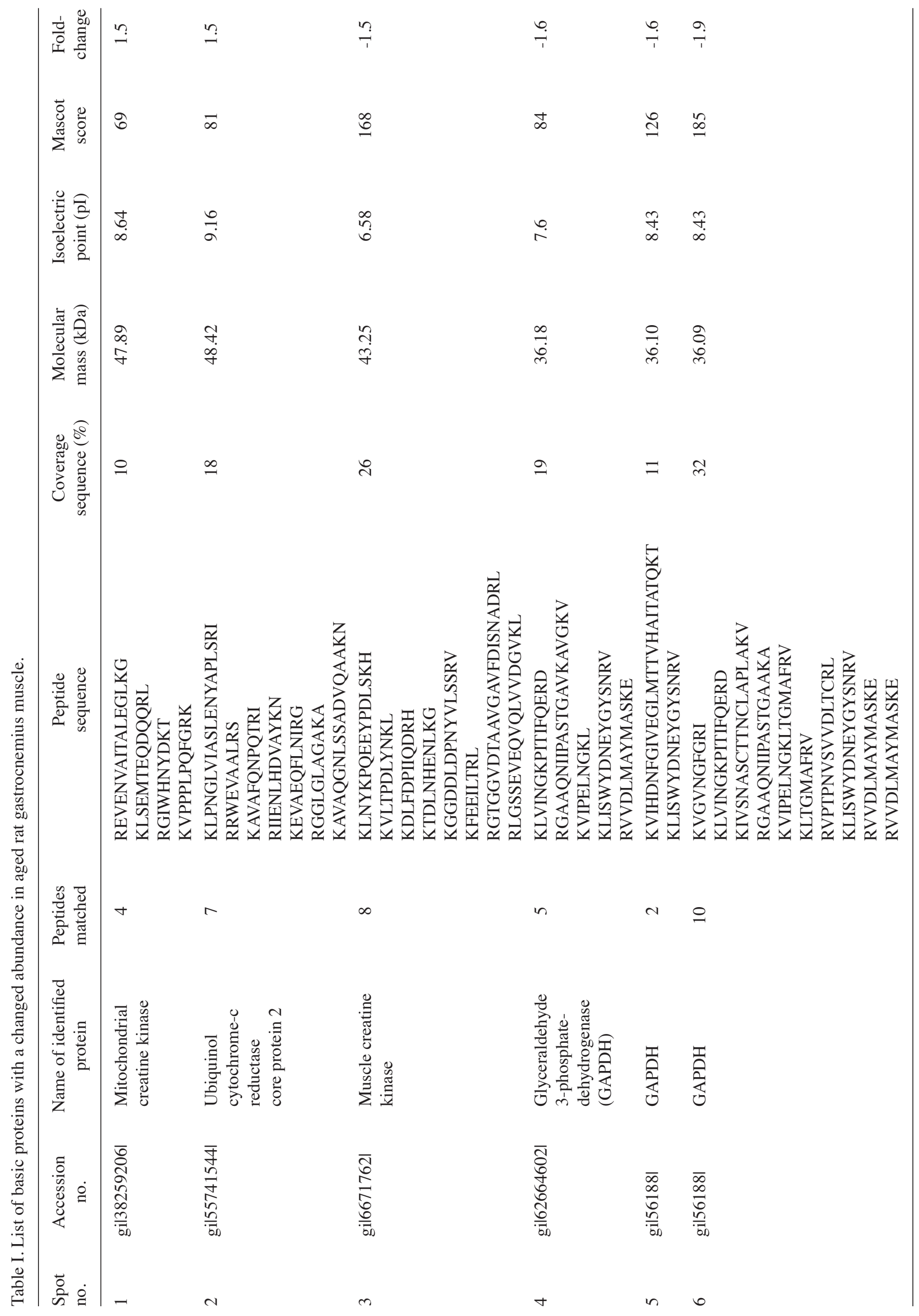


skeletal muscles show changes in their molecular and cellular constellation and clearly exhibit alterations in their glycolytic and aerobic capacity. However, large-scale histological surveys of potential alterations in fiber type distributions with aging have shown variable results (51-54). The results from this report have clearly demonstrated differential changes in the abundance of mitochondrial and glycolytic marker proteins during rat skeletal muscle aging.

Muscle aging appears to be associated with a plethora of cellular and functional abnormalities, including: i) impaired neuromuscular transmission resulting in the loss of entire motor units and cycles of denervation and impaired reinnervation (4), ii) the uncoupling between plasmalemmal excitation and fiber contraction (55), iii) altered functioning of the actomyosin apparatus causing a decline in contractile efficiency (56), iv) an altered equilibrium of growth factors and hormones involved in the maintenance of muscle contraction (57), v) denervation-associated atrophy (2), vi) increased apoptosis (58), vii) impaired regulation of bioenergetic processes (59), viii) disturbed ion handling (60), ix) increased $\mathrm{Ca}^{2+}$-dependent calpain activity triggering mitochondrial and cytoskeletal dysfunction (61), x) a drastically decreased capacity for cellular regeneration (62) and xi) a diminished stress response by molecular chaperones (63). Here, we confirm the idea that a glycolytic-to-oxidative shift occurs in skeletal muscle metabolism during the natural aging process. In the future, the identified mitochondrial and glycolytic enzymes could be useful as potential biomarkers of fiber aging. Since mitochondria are of central importance for energy generation in contractile fibers and because alterations in the density and/or function of mitochondrial enzymes are generally involved in muscle development, muscle differentiation, fiber adaptations and a variety of muscle diseases, the establishment of reliable biomarker signatures is crucial. As shown here, MS-based subproteomics represents a convenient large-scale approach to identify mitochondrial markers of muscle aging.

In conclusion, since large-scale surveys of fiber type distributions during muscle aging have resulted in variable findings, it was of interest to determine potential changes in the abundance of mitochondrial and glycolytic marker proteins in aged skeletal muscle by subproteomics. We showed here that a glycolytic-to-oxidative shift occurs in an animal model of sarcopenia, the 30-month-old Wistar rat. In the long-term, the systematic cataloguing of age-related alterations in the concentration, post-translational modifications, physiological functioning and subcellular localization of mitochondrial enzymes might be useful for the establishment of a comprehensive biomarker signature of skeletal muscle aging. International working groups on skeletal muscle aging have not yet fully established a definition and agreed clinical assessment of sarcopenia as a common geriatric syndrome (64-66). It is therefore crucial to identify and characterize reliable biomarkers of sarcopenia of old age (67). Once suitable combinations of marker enzymes have been characterized, they might be useful for improving diagnostic procedures to differentiate mild versus severe forms of sarcopenia, advance biomedical approaches for monitoring disease progression, expand the set of bioanalytical tools for testing potential side effects of new drug regimes and shed new light on the molecular pathogenesis of sarcopenia of old age.

\section{Acknowledgements}

Research in the author's laboratory was supported by grants from the Science Foundation Ireland and the Higher Education Authority. We thank Anne Kirwan for the excellent technical support.

\section{References}

1. Thomas DR: Sarcopenia. Clin Geriatr Med 26: 331-346, 2010.

2. Vandervoort AA: Aging of the human neuromuscular system. Muscle Nerve 25: 17-25, 2002.

3. Thompson LV: Age-related muscle dysfunction. Exp Gerontol 44: 106-111, 2009.

4. Faulkner JA, Larkin LM, Claflin DR and Brooks SV: Age-related changes in the structure and function of skeletal muscles. Clin Exp Pharmacol Physiol 34: 1091-1096, 2007.

5. Edstrom E, Altun M, Bergman E, Johnson H, Kullberg S, Ramirez-Leon V and Ulfhake B: Factors contributing to neuromuscular impairment and sarcopenia during aging. Physiol Behav 92: 129-135, 2007.

6. Ryall JG, Schertzer JD and Lynch GS: Cellular and molecular mechanisms underlying age-related skeletal muscle wasting and weakness. Biogerontology 9: 213-228, 2008.

7. Frontera WR, Reid KF, Phillips EM, Krivickas LS, Hughes VA, Roubenoff R and Fielding RA: Muscle fiber size and function in elderly humans: a longitudinal study. J Appl Physiol 105: 637-642, 2008

8. Kostek MC and Delmonico MJ: Age-related changes in adult muscle morphology. Curr Aging Sci: April 29, 2011 (Epub ahead of print).

9. Vandervoort AA and Symons TB: Functional and metabolic consequences of sarcopenia. Can J Appl Physiol 26: 90-101, 2001.

10. Kim JS, Wilson JM and Lee SR: Dietary implications on mechanisms of sarcopenia: roles of protein, amino acids and antioxidants. J Nutr Biochem 21: 1-13, 2010.

11. Rolland Y, Dupuy C, Abellan van Kan G, Gillette S and Vellas B: Treatment strategies for sarcopenia and frailty. Med Clin North Am 95: 427-438, 2011.

12. Hurley BF, Hanson ED and Sheaff AK: Strength training as a countermeasure to aging muscle and chronic disease. Sports Med 41: 289-306, 2011.

13. Pahor M and Kritchevsky S: Research hypotheses on muscle wasting, aging, loss of function and disability. J Nutr Health Aging 2: 97-100, 1998.

14. Thomas DR: Loss of skeletal muscle mass in aging: examining the relationship of starvation, sarcopenia and cachexia. Clin Nutr 26: 389-399, 2007.

15. Morley JE: Diabetes, sarcopenia, and frailty. Clin Geriatr Med 24: 455-469, 2008

16. Doran P, Gannon J, O'Connell K and Ohlendieck K: Proteomic profiling of animal models mimicking skeletal muscle disorders. Proteomics Clin Appl 1: 1169-1184, 2007.

17. Doran P, Donoghue P, O'Connell K, Gannon J and Ohlendieck K: Proteomics of skeletal muscle aging. Proteomics 9: 989-1003, 2009.

18. Kanski J, Hong SJ and Schoneich C: Proteomic analysis of protein nitration in aging skeletal muscle and identification of nitrotyrosine-containing sequences in vivo by nanoelectrospray ionization tandem mass spectrometry. J Biol Chem 280: 24261-24266, 2005.

19. Gannon J, Staunton L, O'Connell K, Doran P and Ohlendieck K: Phosphoproteomic analysis of aged skeletal muscle. Int J Mol Med 22: 33-42, 2008.

20. Feng J, Xie H, Meany DL, Thompson LV, Arriaga EA and Griffin TJ: Quantitative proteomic profiling of muscle typedependent and age-dependent protein carbonylation in rat skeletal muscle mitochondria. J Gerontol A Biol Sci Med Sci 63: 1137-1152, 2008

21. O'Connell K, Doran P, Gannon J and Ohlendieck K: Lectin-based proteomic profiling of aged skeletal muscle: decreased pyruvate kinase isozyme M1 exhibits drastically increased levels of N-glycosylation. Eur J Cell Biol 87: 793-805, 2008.

22. Piec I, Listrat A, Alliot J, Chambon C, Taylor RG and Bechet D: Differential proteome analysis of aging in rat skeletal muscle. FASEB J 19: 1143-1145, 2005. 
23. Gelfi C, Vigano A, Ripamonti M, Pontoglio A, Begum S, Pellegrino MA, Grassi B, Bottinelli R, Wait R and Cerretelli P: The human muscle proteome in aging. J Proteome Res 5: 1344-1353, 2006.

24. O'Connell K, Gannon J, Doran P and Ohlendieck K: Proteomic profiling reveals a severely perturbed protein expression pattern in aged skeletal muscle. Int J Mol Med 20: 145-153, 2007.

25. Doran P, Gannon J, O'Connell K and Ohlendieck K: Aging skeletal muscle shows a drastic increase in the small heat shock proteins alphaB-crystallin/HspB5 and cvHsp/HspB7. Eur J Cell Biol 86: 629-640, 2007.

26. Doran P, O'Connell K, Gannon J, Kavanagh M and Ohlendieck K: Opposite pathobiochemical fate of pyruvate kinase and adenylate kinase in aged rat skeletal muscle as revealed by proteomic DIGE analysis. Proteomics 8: 364-377, 2008.

27. Capitanio D, Vasso M, Fania C, Moriggi M, Vigano A, Procacci P, Magnaghi V and Gelfi C: Comparative proteomic profile of rat sciatic nerve and gastrocnemius muscle tissues in ageing by $2-\mathrm{D}$ DIGE. Proteomics 9: 2004-2020, 2009.

28. Gannon J, Doran P, Kirwan A and Ohlendieck K: Drastic increase of myosin light chain MLC-2 in senescent skeletal muscle indicates fast-to-slow fibre transition in sarcopenia of old age. Eur J Cell Biol 88: 685-700, 2009.

29. Donoghue P, Staunton L, Mullen E, Manning G and Ohlendieck K DIGE analysis of rat skeletal muscle proteins using nonionic detergent phase extraction of young adult versus aged gastrocnemius tissue. J Proteomics 73: 1441-1453, 2010.

30. O'Connell K and Ohlendieck K: Proteomic DIGE analysis of the mitochondria-enriched fraction from aged rat skeletal muscle. Proteomics 9: 5509-5524, 2009.

31. Bratic I and Trifunovic A: Mitochondrial energy metabolism and ageing. Biochim Biophys Acta 1797: 961-967, 2010.

32. Parise $\mathrm{G}$ and De Lisio M: Mitochondrial theory of aging in human age-related sarcopenia. Interdiscip Top Gerontol 37: $142-156,2010$

33. Staunton L, O'Connell K and Ohlendieck K: Proteomic profiling of mitochondrial enzymes during skeletal muscle aging. J Aging Res 2011: 908035, 2011.

34. Righetti PG, Castagna A, Antonioli P and Boschetti E: Prefractio nation techniques in proteome analysis: the mining tools of the third millennium. Electrophoresis 26: 297-319, 2005.

35. Horth P, Miller CA, Preckel T and Wenz C: Efficient fractionation and improved protein identification by peptide OFFGEL electrophoresis. Mol Cell Proteomics 5: 1968-1974, 2006.

36. Keidel EM, Dosch D, Brunner A, Kellermann J and Lottspeich F: Evaluation of protein loading techniques and improved separation in OFFGEL isoelectric focusing. Electrophoresis 32 $1659-1666,2011$

37. Fraterman S, Zeiger U, Khurana TS, Rubinstein NA and Wilm M Combination of peptide OFFGEL fractionation and label-free quantitation facilitated proteomics profiling of extraocular muscle. Proteomics 7: 3404-3416, 2007.

38. Chevallet M, Luche $\mathrm{S}$ and Rabilloud T: Silver staining of proteins in polyacrylamide gels. Nat Protoc 1: 1852-1858, 2006.

39. McBride HM, Neuspiel M and Wasiak S: Mitochondria: more than just a powerhouse. Curr Biol 16: R551-R560, 2006.

40. Chan DC: Mitochondria: dynamic organelles in disease, aging, and development. Cell 125: 1241-1252, 2006.

41. Hood DA, Irrcher I, Ljubicic V and Joseph AM: Coordination of metabolic plasticity in skeletal muscle. J Exp Biol 209: 2265-2275, 2006.

42. Schlattner U, Tokarska-Schlattner M and Wallimann T: Mitochondrial creatine kinase in human health and disease. Biochim Biophys Acta 1762: 164-180, 2006.

43. Dudkina NV, Kouril R, Peters K, Braun HP and Boekema EJ: Structure and function of mitochondrial supercomplexes. Biochim Biophys Acta 1797: 664-670, 2010.

44. Ohlendieck K: Proteomics of skeletal muscle glycolysis. Biochim Biophys Acta 1804: 2089-2101, 2010.

45. Hiona A and Leeuwenburgh C: The role of mitochondrial DNA mutations in aging and sarcopenia: implications for the mitochondrial vicious cycle theory of aging. Exp Gerontol 43: 24-33, 2008 .
46. Chabi B, Ljubicic V, Menzies KJ, Huang JH, Saleem A and Hood DA. Mitochondrial function and apoptotic susceptibility in aging skeletal muscle. Aging Cell 7: 2-12, 2008.

47. Figueiredo PA, Powers SK, Ferreira RM, Appell HJ and Duarte JA: Aging impairs skeletal muscle mitochondrial bioenergetic function. J Gerontol A Biol Sci Med Sci 64: 21-33, 2009.

48. Pette D: The adaptive potential of skeletal muscle fibers. Can J Appl Physiol 27: 423-448, 2002.

49. Donoghue P, Doran P, Wynne K, Pedersen K, Dunn MJ and Ohlendieck K: Proteomic profiling of chronic low-frequency stimulated fast muscle. Proteomics 7: 3417-3430, 2007.

50. Staunton L, Jockusch H, Wiegand C, Albrecht T and Ohlendieck K: Identification of secondary effects of hyperexcitability by proteomic profiling of myotonic mouse muscle. Mol Biosyst 7 , 2480-2489, 2011

51. Alnaqeeb MA and Goldspink G: Changes in fiber type, number and diameter in developing and ageing skeletal muscle. J Anat 153: 31-45, 1987

52. Deschenes MR: Effects of aging on muscle fiber type and size. Sports Med 34: 809-824, 2004

53. Lexell J, Taylor CC and Sjostrom M: What is the cause of the ageing atrophy? Total number, size and proportion of different fiber types studied in whole vastus lateralis muscle from 15- to 83-year-old men. J Neurol Sci 84: 275-294, 1988.

54. Lexell J: Human aging, muscle mass, and fiber type composition. J Gerontol A Biol Sci Med Sci 50: 11-16, 1995.

55. Delbono O: Expression and regulation of excitation-contraction coupling proteins in aging skeletal muscle. Curr Aging Sci: April 29, 2011 (Epub ahead of print).

56. Prochniewicz E, Thompson LV and Thomas DD: Age-related decline in actomyosin structure and function. Exp Gerontol 42: 931-938, 2007.

57. Lee CE, McArdle A and Griffiths RD: The role of hormones, cytokines and heat shock proteins during age-related muscle loss. Clin Nutr 26: 524-534, 2007.

58. Marzetti E and Leeuwenburgh C: Skeletal muscle apoptosis, sarcopenia and frailty at old age. Exp Gerontol 41: 1234-1238, 2006.

59. Russ DW and Lanza IR: The impact of old age on skeletal muscle energetics: supply and demand. Curr Aging Sci: 2011 Apr 29 (in press).

60. O'Connell K, Gannon J, Doran P and Ohlendieck K: Reduced expression of sarcalumenin and related $\mathrm{Ca}^{2+}$-regulatory proteins in aged rat skeletal muscle. Exp Gerontol 43: 958-961, 2008.

61. Brule C, Dargelos E, Diallo R, Listrat A, Bechet D, Cottin P and Poussard S: Proteomic study of calpain interacting proteins during skeletal muscle aging. Biochimie 92: 1923-1933, 2010

62. Lorenzon P, Bandi E, de Guarrini F, Pietrangelo T, Schafer R, Zweyer M, Wernig A and Ruzzier F: Ageing affects the differentiation potential of human myoblasts. Exp Gerontol 39: $1545-1554,2004$

63. Kayani AC, Morton JP and McArdle A: The exercise-induced stress response in skeletal muscle: failure during aging. Appl Physiol Nutr Metab 33: 1033-1041, 2008.

64. Lang T, Streeper T, Cawthon P, Baldwin K, Taaffe DR and Harris TB: Sarcopenia: etiology, clinical consequences, intervention, and assessment. Osteoporos Int 21: 543-559, 2010.

65. Cruz-Jentoft AJ, Baeyens JP, Bauer JM, Boirie Y, Cederholm T, Landi F, Martin FC, Michel JP, Rolland Y, Schneider SM, et al: Sarcopenia: European consensus on definition and diagnosis: report of the European working group on sarcopenia in older people. Age Ageing 39: 412-423, 2010.

66. Cruz-Jentoft AJ, Landi F, Topinkova E and Michel JP: Understanding sarcopenia as a geriatric syndrome. Curr Opin Clin Nutr Metab Care 13: 1-7, 2010

67. Pahor M, Manini T and Cesari M: Sarcopenia: clinical evaluation, biological markers and other evaluation tools. J Nutr Health Aging 13: 724-728, 2009 